\title{
EIA Practices Adopted World Wide with Special Reference to Madhya Pradesh India
}

\author{
Mukund Phatak ${ }^{1}$, Dr. Narendra Kanhe2 \\ Associate Professor, Deptt. Of Civil Engg., VNS Instt. Of Technology, Bhopal, M. P. India \\ Professor in Civil Engineering and Principal, Guru Nanak Institute of Engineering and Management, Nagpur \\ M S, India
}

\begin{abstract}
After the study of EIA practices adopted by various countries, it is realized that almost all the countries have a concern for environmental protection. The study of EIA practices adopted reveals that system of EIA evaluation is prevailing in almost all the countries. Even in India, the EIA evaluation is existing since long. Further Ministry of Environment and Forest, Govt. of India has decentralized the process by creating State Level Environmental Impact Assessment Authorities (SEIAA), at state level. This has certainly reduced the time taken to evaluate a proposal and issue an environmental clearance. But it is realized that the degree of subjectivity is still very high in the process of EIA evaluation. Available mathematical tools like Fuzzy Logic etc. may be used for decision making to ensure high degree of objectivity in the process.
\end{abstract}

Key words - Environmental Impact Assessment (EIA),

Submitted Date 20 June 2013

Accepted Date: 25 June 2013

\section{Introduction}

The purpose of the EIA process is to inform decision-makers and the public about the environmental consequences of implementing a proposed project. The EIA document it self is a technical tool that identifies, predicts, and analyzes impacts on the physical environment, as well as social, cultural, and health aspects of the local people dwelling around the proposed project. If the EIA process is carried out genuinely, it identifies alternatives and mitigation measures to reduce the environmental impacts of a proposed project. The EIA process also serves an important procedural role in the overall decision-making process by promoting transparency and public involvement. It is important to note that the EIA process does not guarantee that a project will be given a clearance. If the process reveals that there will be serious environmental impacts then it needs to be rejected. The authorities responsible to keep a balance between Development and Environmental protection, have to take a judicious decision on the basis of this EIA report only. In this paper, an effort is made to study the prevailing environmental laws and process adopted by various countries in the world with special reference to India, especially State of Madhya Pradesh.

\subsection{What is an EIA}

Environmental Impact Assessment (EIA) is "a systematic process that assesses the possible positive or negative impacts that a proposed development project may cause on the environment, together consisting of the natural, social and economic aspects."

The purpose of the assessment is to ensure that decision makers consider the ensuing environmental impacts for deciding whether to proceed with a project or not. The International Association for impact Assessment (IAIA) defines an environmental impact assessment as "the process of identifying, predicting, evaluating and mitigating the biophysical, social and other relevant effects of development proposals prior to major decisions being taken and commitments made.”[1]

An ideal EIA should consist the following [2]:

1. Describe the proposed action, as well as alternatives;

2. Estimate the nature and magnitudes of the likely environmental changes (including the actioninduced effects) ;

3. Identify the relevant human concerns;

4. Define the criteria to be used in measuring the significance of environmental changes, including the relative weighting to be assigned in comparing different kinds of changes;

5. Estimate the significance of the predicted environmental changes, i.e., estimate the impacts of the proposed action; 
6. Make recommendations for one of the following:

1. acceptance of the project

2. remedial action;

3. acceptance of one or more alternatives;

4. rejection;

7. Make recommendations for inspection procedures to be followed after the action has been completed.

Steps (6) and (7) are optional. In some jurisdictions, the impact assessment process stops short of making recommendations.

\section{EIA practices world wide}

EIA practices adopted world wide have been studied and are summarized below.

\subsection{Australia}

The preparation of Environmental Impact Assessment started in Australia with the enactment of National Environment Policy Act (NEPA) in the year 1970 in United States. One has to get the EIA clearance from the State level as well as from Commonwealth (Federal) level. The Environment Protection and Biodiversity Conservation Act 1999 (EPBC) is the current central piece for EIA in Australia on a Commonwealth (Federal) level. This Commonwealth Act does not affect the validity of the States and Territories environmental and development assessments and approvals; rather the EPBC runs as a parallel agency to the State/Territory Systems [3].

The EPBC Act provides a legal framework to protect and manage nationally and internationally important flora, fauna, ecological communities and heritage places-defined in the EPBC Act as matters of 'national environmental significance while various States in Australia have their own EIA assessment process depending the prevailing State environmental laws.

\subsection{Canada}

The Environmental Assessment (EA) in most of the regions in Canada is as per the legal provisions of The Canadian Environmental Assessment Act, 2012 (CEAA 2012). The above act came in to being in the year 2012 and replaced the former Canadian Environmental Assessment Act (1995). Protect components of the environment that are within federal legislative authority from significant adverse environmental effects caused by a proposed project [4]. EA is defined as a planning tool to identify, understand, assess and mitigate, where possible, the environmental effects of a project

\subsection{China}

As per the Environmental Impact Assessment Law (EIA Law) of China, a project proponent has to get the environmental impact assessment prepared prior to construction of the project. However, if a developer completely ignores this requirement and builds a project without submitting an environmental impact statement, the only applicable penalty is that the environmental protection bureau (EPB) may ask the developer to do a make-up environmental assessment within a stipulated time period. If the developer does not complete this make-up assessment within the designated time, then the EPB authorized to impose fine on the developer. In the absence of more stringent enforcement mechanisms in China, many project proponents did not complete legally required environmental impact assessments prior to construction of project [5].

\subsection{Egypt}

The Egyptian Environmental Affairs Agency (EEAA) is responsible for the EIA services. Environmental Impact Assessment (EIA) EIA is implemented in Egypt under the umbrella of the Ministry of state for environmental affairs.

Minister of State for Environmental Affairs was constituted for the first time in Egypt in June 1997. The new ministry is responsible for close collaboration with the national and international development partners, on defining environmental policies, setting priorities and implementing initiatives within a context of sustainable development.

The purpose of EIA is to ensure the protection and conservation of the environment and natural resources including human health aspects against uncontrolled development. The long-term objective is to ensure a sustainable economic development that meets present needs without compromising future generation's ability to meet their own needs. EIA must be performed for new projects and for expansions or modernization of existing establishments according to the Egypt's Environment Law [4]. 


\subsection{European Union ( $E$ U)}

The European Union has established a mix of mandatory and discretionary procedures to assess environmental impacts of a proposed project. Environmental Impact Assessments Directive (known as the EIA Directive) was first introduced in 1985 and was subsequently amended in 1997, 2003, following EU signature of the 1998 and once again in 2009. The initial Directive of 1985 and its three amendments have been codified in Directive 2011/92/EU of 13 December 2011. Under the EU directive, an EIA must provide certain information to comply.[4]There are seven key areas that are required:

1. Description of the project

2. Alternatives that have been considered

3. Description of the environment

4. Description of the significant effects on the environment

5. Mitigation

6. Non-technical summary (EIS)

7. Lack of know-how/technical difficulties

All projects are either classified as Annex 1 or Annex 2 projects depending on their scale. Those lying in Annex 1 are large scale developments such as motorways, chemical works, bridges, power stations etc. These always require an EIA under the Environmental Impact Assessment Directive. Annex 2 projects are smaller in scale than those referred to in Annex 1. Member States must determine whether these projects shall be made, subject to an assessment with a set of criteria set out in Annex 3 of codified Directive 2011/95/EU.

\subsection{The Netherlands}

EIA was implemented in Dutch legislation on September 1, 1987. The categories of projects that require an EIA are summarized in Dutch legislation. The use of thresholds for activities makes sure that EIA is obligatory for those activities that may have considerable impacts on the environment. An EIA report is required for projects and plans which fit these criteria [4].

\subsection{Nepal}

Since the early 1980s Nepal, introduced EIA for major development projects. In the planning history of Nepal, the need for EIA was recognized for the first time by the Environmental Impact Study Project (EISP) under the Department of Soil Conservation in 1982 to develop necessary instruments for integration of EIA in infrastructure development projects. However, the government of Nepal enunciated environment conservation related policies in the period 1985 to1990. In order to enforce this policy and make necessary arrangements, a series of guidelines were developed, thereby incorporating the elements of environmental factors right from the project formulation stage of the development plans and to avoid or minimize adverse effects on the ecological system. In addition, it has also emphasized that EIAs of industry, tourism, water resources, transportation, urbanization, agriculture, forest and other developmental projects be conducted.

In Nepal, the government's Environmental Impact Assessment Guideline of 1993 inspired the enactment of the Environment Protection Act (EPA) of 1997 and the Environment Protection Rules (EPR) of 1997 to internalizing the environmental assessment system. The process institutionalized the EIA process in development proposals and enactment, which makes the EIA legally binding on the prescribed projects [4].

\subsection{New Zealand}

EIA is usually referred to as Assessment of Environmental Effects (AEE) In New Zealand. The first use of EIA's dates back to a Cabinet minute passed in 1974 called Environmental Protection and Enhancement Procedures. With passing of Resource Management Act in the year 1981, an EIA was made mandatory. AEE should include "such detail as corresponds with the scale and significance of the effects that the activity may have on the environment" [4].

\subsection{Russian Federation}

Russia is rich in various natural resources like coal, oil and natural gas in the world and a major consumer as well. From the year 2004, the authority responsible for EIA clearance in Russia has been split in two parts namely, Federal service for monitoring the use of natural resources and Federal Service for Ecological, Technological and Nuclear Control. The two major environmental legislations in Russia are: The Federal Law on 'Ecological Expertise, 1995' and the 'Regulations on Assessment of Impact from Intended Business and Other Activity on Environment in the Russian Federation, 2000'.[6]

\subsection{United States}

In United States of America, The National Environmental Policy Act of 1969 (NEPA) was enacted in the year 1970, As per the U.S. laws of environment, an Environmental Assessment (EA) is compiled to 
determine the need for an Environmental Impact Statement (EIS). NEPA requires that plausible statements as the prospective impacts be disclosed in advance. The purpose of NEPA process is to ensure that the decision maker is fully informed of the environmental aspects and consequences prior to making the final decision.

An Environmental Assessment (EA) is an environmental analysis prepared to know whether a federal action would significantly affect the environment and thus require a more detailed Environmental Impact Statement (EIS). The certified release of an Environmental Assessment results in either a Finding of No Significant Impact (FONSI) or an Environmental Impact Statement (EIS).

Eccleston reports that the NEPA regulations barely mention preparation of EAs. This is because the EA was originally intended to be a simple document used in relatively rare instances where an agency was not sure if the potential significance of an action would be sufficient to trigger preparation of an EIS. But today, because EISs are so much longer and complicated to prepare, federal agencies are putting great efforts to avoid preparing EISs by using EAs, even in cases where the use of EAs may be inappropriate. The ratio of EAs that are being issued compared to EISs is about 100 to 1 .

The EA becomes a draft public document when notice of it is published, usually in a newspaper of general circulation in the area affected by the proposal. There is a 15 day review period required for an Environmental Assessment (30 days if exceptional circumstances) while the document is made available for public commentary, and a similar time for any objection to improper process. Commenting on the Draft EA is typically done in writing or email, submitted to the lead action agency as published in the notice of availability.

An EA does not require a public hearing for verbal comments. Following the mandated public comment period the lead action agency will respond to any comments received and certify either a FONSI or a Notice of Intent (NOI) to prepare an EIS in its public environmental review record. The preparation of an EIS then becomes a similar but more lengthy and expensive process [4].

\subsection{Trans boundary initiatives}

Almost every country of the world has environmental conservation as its priority within their boundary. Each country has suitable environmental laws and a system of EIA evaluation has been derived by each one. But Environmental threats do not limit to national borders. International pollution can have detrimental effects on the atmosphere, oceans, rivers, aquifers, farmland, the weather and biodiversity. Global climate change is transnational. Specific pollution threats include acid rain, radioactive contamination, debris in outer space, stratospheric ozone depletion and toxic oil spills. Environmental protection is inherently a cross-border issue and has led to the creation of transnational regulation via multilateral and bilateral treaties. The United Nations Conference on the Human Environment (UNCHE or Stockholm Conference) held in Stockholm in 1972 and the United Nations Conference on the Environment and Development (UNCED or Rio Summit, Rio Conference, or Earth Summit) held in Rio de Janeiro in 1992 were in the creation of about 1,000 international instruments that include at least some provision related to the environment and its protection.

The United Nations Economic Commission for Europe's Convention on Environmental Impact Assessment in a Trans boundary Context was negotiated to provide an international legal framework for trans boundary EIA.[7]

However, as there is no universal legislature or administration with a comprehensive mandate, most international treaties exist parallel to one another and are further developed without the benefit of consideration being given to potential conflicts with other agreements. There is also the issue of international enforcement. This has led to duplications and failures, in part due to an inability to enforce agreements.

\subsection{EIA practices in India}

The Ministry of Environment and Forest (MOEF), Govt. of India is the nodal agency to grant Environmental Clearance to a project. The main laws in action are the Water Act (1974), the Wildlife Protection Act (1972), the Air (Prevention and Control of Pollution) Act (1981) and the Environment Protection Act (1986).

The Environment Impact Assessment (EIA) notification of 14th Sept 2006 issued by the Ministry of Environment and Forest (MOEF), Govt. of India has made it mandatory for all developmental projects to obtain prior environmental clearance. These activities have been covered under eight various categories. A systematic process has been laid down in the notification for giving the environmental clearance. Specific time frame has also been allotted to various steps involved in the process of prior environmental clearance. With the intention to simplify the process, all the projects have been classified in A or B categories depending on the threshold limit.

A category Projects are cleared by MOEF while Prior Environmental Clearance to B Category Projects is accorded by The State Level Environmental Assessment Authority (SEIAA) constituted in various states by the Ministry [8]. It is observed that clearance is accorded on the basis of the information given by the proponent. The various parameters are not given any credit depending on the degree of damage they may cause. Human 
factor in the clearance process plays a decisive role defeating its objectivity. It is proposed to develop a systematic model for analysis of the probable threats to the environment due to a proposed activity.

\section{EIA practices by SEIAA of Madhya Pradesh}

As per the provision of EIA Notification of 14th Sept. 2006 as mentioned above, the Ministry of Environment and Forest (MOEF), Govt. of India in consultation with the State Government of Madhya Pradesh, constituted, The State Level Environment Impact Assessment Authorities (SEIAA) in the state. This authority has been delegated the powers by the Ministry to assess the mining projects up to 50 Hects. proposed in the state. The authority is functioning in the state of Madhya Pradesh for the last 5 years [9]. A State Expert Appraisal Committee (SEAC) has also been constituted along with SEIAA, to give technical opinion to the authority. The procedure adopted by SEIAA of M P is the same as specified by the MOEF in its EIA notification of 2006.

\subsection{Mandatory steps to be followed by SEIAA of MP}

Following steps will be followed by SEIAA to accord Prior Environmental Clearance to a mining project [10].

\section{Screening}

After a careful scrutiny of the application submitted in the prescribed form I by the proponent, it is decided by the SEAC, whether the project requires further environmental studies for preparation of environmental impact assessment (EIA) before granting a prior environmental clearance to the project. This further categorizes the project into B1 or B2 (B1 requiring EIA report, while B2 does not require it, as per the provision of EIA notification).

\section{Scoping}

All the B1 category projects are suggested a comprehensive terms of reference (TOR) addressing all relevant environmental concerns in respect of the proposed activity. The SEAC finalizes the Terms of reference (TOR) on the basis of the information furnished by the project proponent and the presentation made before the expert committee. SEAC visits the proposed site if necessary. I or IA.

The TOR is conveyed to the proponent within a period of 60 days from the date of submission of form

\section{Public Consultations:-}

It is the most important step involved in the whole process. The public consultation has been included in the process to ascertain the concerns of the affected local people and others who have a possible stake in the environmental impacts of the projects. Public consultation is mandatory for all ' $\mathrm{A}$ ' and ' $\mathrm{B}$ ' category projects except some exemptions. In public consultation process objections and suggestions are collected from the public during meeting at proposed site or received in writing.

Public hearing is conducted at site in the presence of District Collector or his representative and officers of M P State Pollution Control Board (MPPCB). The concerned Regional Office of MPPCB conducts the public consultation at site and sends the report to the authority for its consideration.

\section{Appraisals}

It includes the detailed scrutiny of, the application, final EIA report submitted by the proponent and the objections and suggestions raised during public consultation. The Expert Appraisal Committee (SEAC) takes a final decision in the matter in its meeting and accordingly recommends for granting or rejecting the prior environmental clearance to the authority. The committee makes categorical recommendations to regulatory authority for grant of prior environmental clearance on necessary terms and conditions or rejection of application mentioning reasons for same.

\section{Grant or Rejection of Prior Environmental Clearance:-.}

The regulatory authority considers the recommendations of the appraisal committee and takes a final decision in its meeting. The decision is conveyed to the proponent by the authority, within 45 days from the date of receipt of the recommendation of the appraisal committee.

\subsection{Status of the mining projects submitted to SEIAA of M P}

Madhya Pradesh being a state of rich mineral wealth has the maximum number of projects under consideration of the state SEIAA. As per the information available on the official web site of the authority (www.mpseiaa.nic.in), there are 881 mining projects either cleared or under consideration of the authority, while the total tally of the project has reached 1118 by $20^{\text {th }}$ Jan 2013 [9]. 
The number of projects handled by the M P SEIAA is huge as compared to the resources available. The figure is likely to increase tremendously due to the directives issued by the Hon'ble Supreme court of India, making the Environmental Clearance mandatory to all the mines irrespective of area. As per the guidelines of the EIA notification of 2006, the mines having an area of less than 5 Hects were exempted. In the state of Madhya Pradesh, there were huge number of mines which had an area slightly less than 5 ha, to suit the convenience of the mine owner. Because of the new directives, all the mines need to get an Environmental Clearance putting lot of work pressure on the authority. Here it is worth mentioning that a clause of deemed clearance is a part of EIA Notification. Hence it is the prime responsibility of the authority to clear all the projects within the stipulated time frame. This gives an indication about the degree of scrutiny at the authority level with the available resources.

The Environmental Impact Assessment (EIA) experience in India and the Madhya Pradesh, indicates that the lack of timely availability of reliable and authentic environmental data, non availability of the qualified consultant specially in the State, limited resources available with the appraisal authorities have been the major bottle necks in achieving the full benefits of EIA process. As reported by few project proponents, SEIAA is asking for irrelevant information in many cases just to avoid the deemed clearance to the project.

\section{Conclusions}

Reviewing the practices adopted world wide, we find that in almost all the major countries, the system of EIA preparation and evaluation is existing. The only difference is the process of assessment is guided by the respective environmental laws prevailing in that country, but the basic objective is to safeguard the environment.

This can only be achieved by a scientific approach for EIA preparation and its systematic assessment before arriving at a decision. In India, the responsible body for the assessment is the Ministry of Environment and Forest (MOEF) at national level and the State Level Environment Impact Assessment Authority, (SEIAA) at the state level.

The Ministry has constituted various state level authorities (SEIAAs) for the speedy disposal of the EIA proposals. The idea behind delegation of powers to state authority for Environment Impact Assessment of 'B' category projects at the state level is to facilitate the project proponents by disposing their cases at state capital. Our efforts should be such that the degree of subjectivity in the whole process should be reduced, making everything as much transparent as possible. Available mathematical techniques like Fuzzy Logic may be used as a decision making tool to reduce subjectivity in the processes.

All 'B' category projects of the state are assessed by SEIAA of M P, but it seems that the authority is not performing up to the mark as far as EIA clearance and post clearance monitoring is concerned. In the absence of the regular capacity building of the members of SEIAA and SEAC by the Ministry and influence of local factors, the consistent decisions at state level can not be ensured. A mechanism should also be developed by the Ministry to review few sample decisions taken by authority on its behalf.

\section{Reference}

[1]. Principles of Environmental Impact Assessment Best Practice, International Association for Impact Assessment 1999.

[2]. Scientific Committee On Problems of the Environment (SCOPE), Scope 5 - Environmental Impact Assessment, Chapter 3.

[3]. Elliott, M. \& Thomas, I. (2009) Environmental Impact Assessment in Australia; Theory and Practice, $5^{\text {th }}$ Edition, Federation Press, Sydney.

[4]. Environmental Impact Assessment Wikipedia, the free encyclopedia.

[5]. Wang, Alex (2007/02/05) "Environmental Protection in China: the role of law"

[6]. Department of Environmental Protection, Russia.

[7]. Convention on Environmental Impact Assessment in a Trans boundary context (Espoo, 1991).

[8]. S. O. 1533, EIA Notification issued by the Ministry of Environment and Forest, Govt. of India on $14^{\text {th }}$ Sept. 2006.

[9]. Www.mpseiaa.nic.in official web site of SEIAA of M P referred on $31^{\text {st }}$ Jan 2013.

[10]. Mukund Phatak and Dr. Narendra Kanhe, Critical Analysis of According Prior Environmental Clearance 